\title{
New relationship between Young's modulus and nonideally sharp indentation parameters
}

\author{
Dejun Ma \\ Surface Engineering Research Institute, Chinese Mechanical Engineering Society, \\ Beijing 100072, People's Republic of China \\ Chung Wo Ong ${ }^{\text {a) }}$ and Sing Fai Wong \\ Department of Applied Physics and Materials Research Center, The Hong Kong Polytechnic \\ University, Hung Hom, Kowloon, Hong Kong, People's Republic of China
}

(Received 5 January 2004; accepted 6 April 2004)

\begin{abstract}
Both analysis and numerical calculations have been carried out to investigate the relationship between Young's modulus and nonideally sharp indentation parameters. The results confirm that there exists an approximate one-to-one correspondence between the ratio of nominal hardness/reduced Young's modulus $\left(H_{\mathrm{n}} / E_{\mathrm{r}}\right)$ and the ratio of elastic work/total work $\left(W_{\mathrm{e}} / W\right)$ for any definite bluntness ratio $\left(\Delta h / h_{\mathrm{m}}\right)$ of a nonideally sharp indenter. Based on this relationship, the Young's modulus of the indented material can be determined just from the values of $H_{\mathrm{n}}, W_{\mathrm{e}}$, and $W$, which are directly measurable quantities in an indentation test.
\end{abstract}

\section{INTRODUCTION}

Depth-sensing indentation techniques have been widely used for determining the mechanical properties of materials on small scales. ${ }^{1-5}$ Young's modulus is one of the most commonly concerned material properties measured by this kind of technique. Unlike the uniaxial tensile test, the measurement of Young's modulus by indentation is indirect and approximate because of the complicated nonlinearity involved in an indentation process and the difficulty in deriving the analytical relationship between Young's modulus of the indented material and indentation parameters. Accordingly, the accuracy of the measurement would rely heavily on the concrete functional form of the approximate relationship established for the determination of Young's modulus.

A well-known relationship developed by Oliver and $\mathrm{Pharr}^{4}$ is given by

$$
E_{\mathrm{r}}=\frac{\sqrt{\pi}}{2 \beta} \frac{S_{\mathrm{u}}}{\sqrt{A\left(h_{\mathrm{cm}}\right)}},
$$

where $S_{\mathrm{u}}$ is the initial slope of unloading curve, $E_{\mathrm{r}}$ is the reduced modulus and related with the Young's modulus $E$ and Poisson's ratio $v$ of the indented material and those $\left(E_{\mathrm{i}}, \nu_{\mathrm{i}}\right)$ of the indenter by the equation $1 / E_{\mathrm{r}}=\left(1-v^{2}\right) / E+$ $\left(1-v_{\mathrm{i}}^{2}\right) / E_{\mathrm{i}}, \beta$ is a constant depending on the shape of the

\footnotetext{
a) Address all correspondence to this author. e-mail: apacwong@inet.polyu.edu.hk DOI: 10.1557/JMR.2004.0274
}

indenter, $A\left(h_{\mathrm{cm}}\right)$ is the projected contact area at the maximum contact depth $h_{\mathrm{cm}}$ corresponding to the maximum indentation depth $h_{\mathrm{m}}$ and load $P_{\mathrm{m}}$. According to Oliver and Pharr, $A\left(h_{\mathrm{cm}}\right)$ needs to be estimated from the unloading curve before relationship (1) is applied.

To eliminate the reliance on $A\left(h_{\mathrm{cm}}\right)$, in recent years, great efforts have been made to investigate the relationship between hardness, Young's modulus and indentation work on the basis of numerical analytical analysis. It is found that for ideally sharp indenter, ${ }^{6-10}$ an approximate one-to-one correspondence exists between the ratio of hardness to reduced Young's modulus and the ratio of elastic work to total work. A similar relationship for spherical indentation ${ }^{11}$ with any definite ratio of indentation depth to spherical radius in the range of $0.05-0.5$ has also been revealed. These relationships can be expressed in an implicit form such as

$$
H / E_{\mathrm{r}}=f\left(W_{\mathrm{e}} / W\right),
$$

where $H$ is the hardness and defined as the maximum indentation load $P_{\mathrm{m}}$ divided by $A\left(h_{\mathrm{cm}}\right)$, i.e., $H=P_{\mathrm{m}} /$ $A\left(h_{\mathrm{cm}}\right) ; W_{\mathrm{e}}$ and $W$ are the elastic work and total work, which are equal to the areas under the unloading and loading curves, respectively. By combining Eq. (1) with Eq. (2) to eliminate $A\left(h_{\mathrm{cm}}\right), E_{\mathrm{r}}$ can be determined as

$$
E_{\mathrm{r}}=\left[\pi /(2 \beta)^{2}\right] f\left(W_{\mathrm{e}} / W\right)\left[S_{\mathrm{u}}^{2} / P_{\mathrm{m}}\right] .
$$

It is obvious that when Eq. (3) is used for the determination of Young's modulus, the estimate on the projected contact area is no longer needed. This feature differentiates the relationship from that of Oliver and Pharr. For the convenience of distinction, Eq. (1) is referred as 
the slope relationship, and Eq. (3) is referred as the slope\&energy relationship. Though being different in principle, the two relationships are in common to rely on the use of the initial unloading slope and Eq. (1). Considering the difficulty in getting accurate measurement of the initial unloading slope, the precision of the determination of Young's modulus remains still a fundamental question.

In this paper, we reveal a new approximate relationship between Young's modulus and nonideally sharp indentation parameters. The relationship relates the ratio of nominal hardness/reduced Young's modulus $\left(H_{\mathrm{n}} / E_{\mathrm{r}}\right)$ with the ratio of elastic work/total work $\left(W_{\mathrm{e}} / W\right)$ for any definite bluntness ratio of a nonideally sharp indenter. Different from the definition of the conventional hardness $H=P_{\mathrm{m}} / A\left(h_{\mathrm{cm}}\right)$, the nominal hardness $H_{\mathrm{n}}$ introduced in this study is defined as $H_{\mathrm{n}}=P_{\mathrm{m}} / A\left(h_{\mathrm{m}}\right)$, where $h_{\mathrm{m}}$ and $A\left(h_{\mathrm{m}}\right)$ are the maximum indentation depth and the crosssection area of the tip specified at $h_{\mathrm{m}}$. As a remarkable feature of the relationship, neither the contact area nor the initial unloading slope is needed. Instead, only the indentation work, the maximum indentation load and depth, and the bluntness quantity of the indenter are required. Therefore, it is named as the pure energy relationship.

\section{MODELING OF NONIDEALLY SHARP INDENTER}

In nanoindentation tests, a Berkovich indenter is the most widely used type of indenter, and inevitably, it always exhibits some degree of bluntness near the tip. For simplicity, the blunt or the nonideal Berkovich indenter is approximated by a nonideally conical one with a spherical cap at the tip. A schematic representation of the indenter is shown in Fig. 1, where $\theta$ is the half-included angle of the modeling indenter and selected to be $70.3^{\circ}$ to ensure the modeling indenter with the same area-to-depth ratio as that of the real Berkovich indenter at large indentation depths, $R$ is the radius of the spherical cap, which can be evaluated by applying the same principle at shallow indentation depths, $\Delta h$ is the distance between

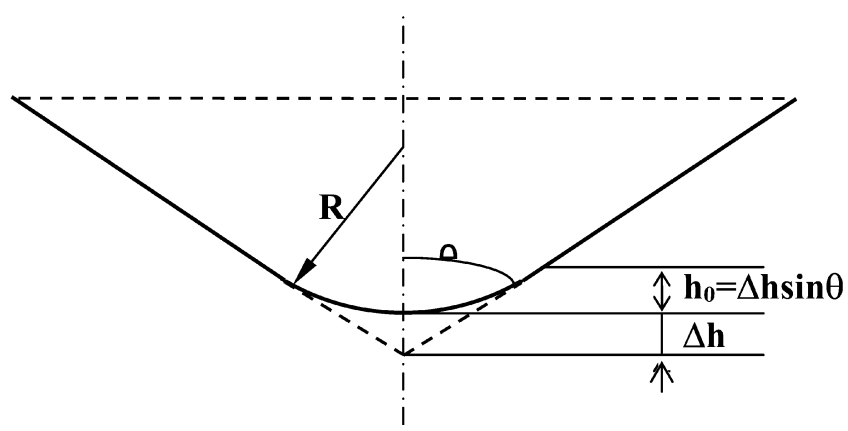

FIG. 1. Schematic representation of a nonideally conical indenter with a spherical cap at the tip. the apex of the ideally conical shape and the bottom of the spherical cap, and $h_{0}$ is the distance from the bottom of the spherical cap to the boundary between the spherical and conical contact, and $h_{0}=\Delta h \sin \theta$. It is obvious that the nonideally conical indenter can be specified with either $\theta$ and $R$ or $\theta$ and $\Delta h$. In fact, $\Delta h, R$, and $\theta$ are related by the equation $\Delta h=(1 / \sin \theta-1) R$, so for a definite $\theta$, the use of $R$ or $\Delta h$ is equivalent. In this study, $\Delta h$ is used in modeling the nonideally sharp indenter to indicate the degree of its bluntness. Thus, $\Delta h$ is defined to be the absolute bluntness of the modeled non-ideally sharp indenter, and the ratio $\Delta h / h_{\mathrm{m}}$ is defined to be the relative bluntness of the same indenter.

\section{ANALYTICAL ANALYSIS}

The relationship between Young's modulus and indentation parameters is investigated first by using an analytical method. Regarding to the nonideal indenter geometry, the following three situations are considered

\section{A. $0 \leqslant \Delta h / h_{\mathrm{m}} \leqslant 0.2$}

Under this condition, we apply the assumption suggested by Cheng et al. ${ }^{12}$ i.e. an indentation by a conical indenter with spherical tip may be viewed as an indentation by an ideally sharp indenter with its initial tip position shifted by $\Delta h$ shown in Fig. 1 . Therefore, the indentation load $P$ as a function of indentation depth $h$ during loading can be approximated by

$$
P=\mathrm{C}(h+\Delta h)^{2},
$$

where $\mathrm{C}$ is a constant, and its value only depends on the elastoplastic properties of the indented material and the indenter material. By integrating Eq. (4), the indentation work $W$ in the whole loading process can be given by

$$
W=\int_{0}^{h_{\mathrm{m}}} P \mathrm{~d} h=P_{\mathrm{m}} h_{\mathrm{m}} \frac{1}{3} \frac{\left[\left(1+\Delta h / h_{\mathrm{m}}\right)^{3}-\left(\Delta h / h_{\mathrm{m}}\right)^{3}\right]}{\left(1+\Delta h / h_{\mathrm{m}}\right)^{2}},
$$

let

$$
f_{\Delta 1}\left(\Delta h / h_{\mathrm{m}}\right)=\frac{1}{3} \frac{\left[\left(1+\Delta h / h_{\mathrm{m}}\right)^{3}-\left(\Delta h / h_{\mathrm{m}}\right)^{3}\right]}{\left(1+\Delta h / h_{\mathrm{m}}\right)^{2}},
$$

then

$$
W=P_{\mathrm{m}} h_{\mathrm{m}} f_{\Delta 1}\left(\Delta h / h_{\mathrm{m}}\right) \quad .
$$

To investigate the unloading process, we start the analysis from considering the contact pressure distribution between a nonideally conical indenter and a semiinfinite solid. According to Yu and Blanchard's model ${ }^{13}$ for elastic perfectly-plastic material, the contact pressure should be a constant around the contact center, and 
gradually decreases to zero near the contact boundary. We refer to this model and use a more general pressure distribution, namely an elliptic pressure distribution, to be the first approximation for a real case where the sample is generally an elastic-plastic material. Consequently, with the same pressure distribution the unloading behavior of the nonideally conical indenter indented into an elastoplastic solid is approximately equivalent to that of an imaginary spherical indenter indented into an ideal semi-infinite elastic solid. A schematic representation of the equivalence during unloading and the parameters used in the following discussion are shown in Fig. 2. Applying Hertz's solution ${ }^{14}$ to the elastic contact between a spherical body and a semi-infinite solid, the load $P_{\mathrm{u}}$ in an unloading process is given by

$$
P_{\mathrm{u}}=\frac{4}{3} E_{\mathrm{r}} R_{\mathrm{V}}^{0.5}\left(h-h_{\mathrm{r}}\right)^{1.5},
$$

where $h_{\mathrm{r}}$ is the residual impression depth of a nonideally conical indenter. $h-h_{r}$ is the distance between the apex of the nonideally conical indenter and the position of its completely unloading, and its quantity equals the penetrating displacement of the imaginary spherical indenter into a semi-infinite elastic solid. $R_{\mathrm{V}}$ is the radius of the imaginary spherical indenter, and it is related with the contact radius $a$ by the following equation

$$
R_{\mathrm{V}}=\frac{4 E_{\mathrm{r}}}{3 P_{\mathrm{u}}} a^{3}
$$

Integrating Eq. (8), the elastic work $W_{\mathrm{e}}$ done in the unloading process by load $P_{\mathrm{u}}$ can be obtained

$$
W_{\mathrm{e}}=\int_{h \mathrm{r}}^{h \mathrm{~m}} P_{\mathrm{u}} \mathrm{d} h=\frac{1}{2.5} P_{\mathrm{m}}\left(h_{\mathrm{m}}-h_{\mathrm{r}}\right)
$$

Let

$$
h_{\mathrm{em}}=h_{\mathrm{m}}-h_{\mathrm{r}} .
$$

The equation (10) can be rewritten as

$$
W_{\mathrm{e}}=\frac{1}{2.5} P_{\mathrm{m}} h_{\mathrm{em}}
$$

Dividing the two sides of Eq. (12) by Eq. (7) yields

$$
\frac{h_{\mathrm{em}}}{h_{\mathrm{m}}}=2.5 f_{\Delta 1}\left(\Delta h / h_{\mathrm{m}}\right)\left(\frac{W_{\mathrm{e}}}{W}\right) \text {. }
$$

Substituting Eqs. (9) and (11) into Eq. (8), the maximum indentation load $P_{\mathrm{m}}$, i.e., the load $P_{\mathrm{u}}$ at the moment of initially unloading can be expressed as

$$
P_{\mathrm{m}}=P_{\mathrm{u} \mid h=h_{\mathrm{m}}}=\frac{4}{3} E_{\mathrm{r}} a_{\mathrm{m}} h_{\mathrm{em}},
$$

where $a_{\mathrm{m}}$ is the maximum contact radius, and related with the maximum contact depth $h_{\mathrm{cm}}$ by

$$
a_{\mathrm{m}}=\left(h_{\mathrm{cm}}+\Delta h\right) \tan \theta .
$$

There exist two expressions for estimating $h_{\mathrm{cm}}$

$$
h_{\mathrm{cm}}=h_{\mathrm{m}}-0.75 \frac{P_{\mathrm{m}}}{S_{\mathrm{u}}},
$$

and

$$
h_{\mathrm{cm}}=1.2\left(h_{\mathrm{m}}-\frac{P_{\mathrm{m}}}{S_{\mathrm{u}}}\right) \text {. }
$$

They are suggested by Oliver et $\mathrm{al}^{4}$ and Loubet et al., ${ }^{15}$ respectively. By differentiating Eq. (8) at the maximum indentation depth $h_{\mathrm{m}}, S_{\mathrm{u}}$ can be determined, and Eqs. (16) and (17) can be rewritten as

$$
\begin{gathered}
h_{\mathrm{cm}}=h_{\mathrm{m}}-0.5 h_{\mathrm{em}}, \\
h_{\mathrm{cm}}=1.2 h_{\mathrm{m}}-0.8 h_{\mathrm{em}} .
\end{gathered}
$$

In this analysis, we take the intermediate between the two expressions

$$
h_{\mathrm{cm}}=1.1 h_{\mathrm{m}}-0.6 h_{\mathrm{em}} .
$$

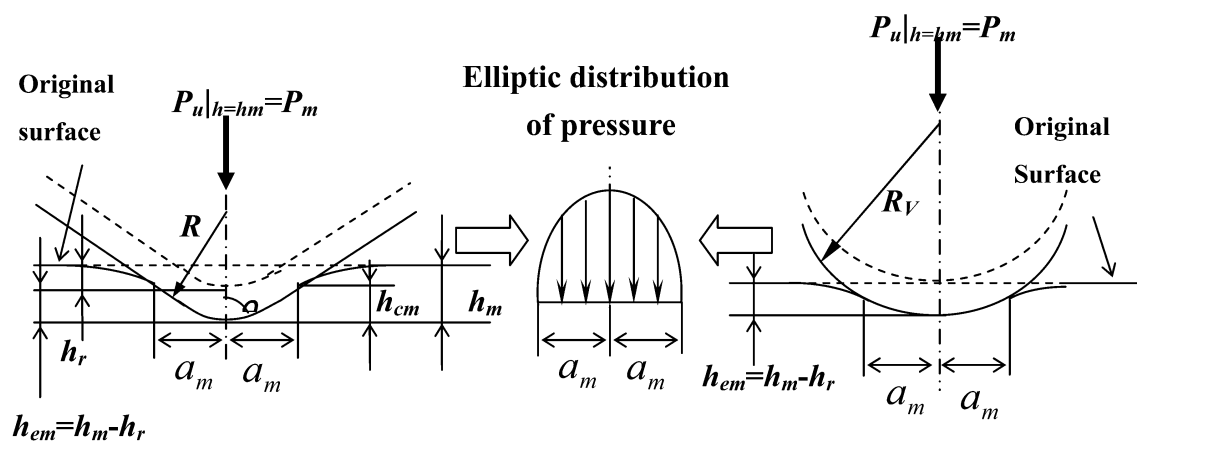

Elastoplastic material

Elastic material

FIG. 2. Schematic representation of the equivalence between the unloading behavior of a nonideally conical indenter indented into an elastoplastic solid and that of an imaginary spherical indenter indented into a semi-infinite elastic solid. 
Through combining Eqs. (14), (15), and (20), and considering the definition of nominal hardness, we obtain

$$
\begin{aligned}
H_{\mathrm{n}}= & \frac{P_{\mathrm{m}}}{A\left(h_{\mathrm{m}}\right)}=\frac{(4 / 3) E_{\mathrm{r}} a_{\mathrm{m}} h_{\mathrm{em}}}{24.5\left(\Delta h+h_{\mathrm{m}}\right)^{2}} \\
= & \frac{(4 / 3) E_{\mathrm{r}}\left[1.1-0.6\left(h_{\mathrm{em}} / h_{\mathrm{m}}\right)\right.}{24.5\left(1+\Delta h / h_{\mathrm{m}}\right)^{2}} .
\end{aligned}
$$

Substituting Eq. (13) into Eq. (21), a final relationship between Young's modulus and indentation parameters corresponding to the condition of $0 \leqslant \Delta h / h_{m} \leqslant 0.2$ is obtained as

$$
\frac{H_{\mathrm{n}}}{E_{\mathrm{r}}}=\frac{\begin{array}{c}
f_{\Delta 1}\left(\Delta h / h_{\mathrm{m}}\right) \tan \theta\left[1.1-1.5 f_{\Delta 1}\left(\Delta h / h_{\mathrm{m}}\right)\right. \\
\left.\left(W_{\mathrm{e}} / W\right)+\left(\Delta h / h_{\mathrm{m}}\right)\right]\left(W_{\mathrm{e}} / W\right)
\end{array}}{7.35\left(1+\Delta h / h_{\mathrm{m}}\right)^{2}} .
$$

\section{B. $\Delta h / h_{m} \geqslant 1 / \sin \theta$}

Under this condition, the spherical geometry dominates the indentation responses. According to Tabor, ${ }^{16}$ two critical states exist in a spherical indentation test. The one is the perfect elastic, and the other is the fully plastic. For the perfect elastic indentation, the load $P$ is given by $\mathrm{Hertz}^{14}$ as

$$
P=\frac{4}{3} E_{1} R^{0.5} h^{1.5}
$$

For the fully plastic indentation, Alcala et al. ${ }^{17}$ showed that the load $P$ in a loading process is proportional to $h^{(1+0.5 n)}$

$$
P \propto h^{(1+0.5 n)},
$$

where $n$ is the strain hardening exponent of the indented material. Considering a general intermediate case involving both elastic and partly plastic deformation, and noticing that $n$ in Eq. (24) falls in the range of $0-0.5$ for most metals and alloys, the power law index of the indentation depth $h$ should lie in the range of 1.0-1.5. This allows us to take the mean value of 1.25 , such that the loading curve of a general spherical indentation can be approximated by

$$
P=K h^{1.25},
$$

where $\mathrm{K}$ is a constant and its value is only related to the elastoplastic properties of the indented material and the indenter material. Therefore, the indentation work $W$ in the whole loading process can be given as

$$
W=\int_{0}^{h_{\mathrm{m}}} P \mathrm{~d} h=\frac{1}{2.25} P_{\mathrm{m}} h_{\mathrm{m}} .
$$

As for the unloading process, we apply the same model as that used in Section III. A. Consequently, the ratio of $h_{\mathrm{em}} / h_{\mathrm{m}}$ can be determined by dividing Eq. (26) by Eq. (12), that is

$$
\frac{h_{\mathrm{em}}}{h_{\mathrm{m}}}=\left(\frac{2.5}{2.25}\right)\left(\frac{W_{\mathrm{e}}}{W}\right) .
$$

The determination of $a_{\mathrm{m}}$ depends on the ratio of $h_{\mathrm{cm}} /$ $h_{0}$, i.e.,

$$
a_{\mathrm{m}}=\left\{\begin{array}{ll}
\left(h_{\mathrm{cm}}+\Delta h\right) \tan \theta & , h_{\mathrm{cm}} / h_{0} \geqslant 1 \\
\sqrt{2 R h_{\mathrm{cm}}-h_{\mathrm{cm}}^{2}}, & h_{\mathrm{cm}} / h_{0}<1
\end{array} .\right.
$$

Considering Eq. (20) and $h_{0}=\Delta h \sin \theta$, we obtain

$$
\frac{h_{\mathrm{cm}}}{h_{0}}=\frac{1.1-0.6\left(h_{\mathrm{em}} / h_{\mathrm{m}}\right)}{\left(\Delta h / h_{\mathrm{m}}\right) \sin \theta} \text {. }
$$

Substituting Eq. (27) into Eq. (29) yields

$$
\frac{h_{\mathrm{cm}}}{h_{0}}=\frac{1.1-(2 / 3)\left(W_{\mathrm{e}} / W\right)}{\left(\Delta h / h_{\mathrm{m}}\right) \sin \theta} \text {. }
$$

Let $h_{\mathrm{cm}} / h_{0}=1$ and $\left(W_{\mathrm{e}} / W\right)_{1}$ represent the corresponding value of $W_{\mathrm{e}} / W$, then

$$
\begin{aligned}
\left(W_{\mathrm{e}} / W\right)_{1} & =\left(W_{\mathrm{e}} / W\right)_{\mid h_{\mathrm{cm}} / h_{0}=1} \\
& =1.5\left[1.1-\left(\Delta h / h_{\mathrm{m}}\right) \sin \theta\right] .
\end{aligned}
$$

Therefore, Eq. (28) can be rewritten as

$a_{\mathrm{m}}=\left\{\begin{array}{cl}\left(h_{\mathrm{cm}}+\Delta h\right) \tan \theta & , W_{\mathrm{e}} / W \leqslant\left(W_{\mathrm{e}} / W\right)_{1} \\ \sqrt{2 R h_{\mathrm{cm}}-h_{\mathrm{cm}}^{2}}, & W_{\mathrm{e}} / W>\left(W_{\mathrm{e}} / W\right)_{1}\end{array}\right.$.

Combining Eqs. (14), (20), and (32), and considering $R=[\sin \theta /(1-\sin \theta)] \Delta h$ and the definition of the nominal hardness, we obtain

$$
\begin{aligned}
& H_{\mathrm{n}}=\frac{P_{\mathrm{m}}}{A\left(h_{\mathrm{m}}\right)}=\frac{(4 / 3) E_{\mathrm{r}} a_{\mathrm{m}} h_{\mathrm{em}}}{\pi\left(2 R h_{\mathrm{m}}-h_{\mathrm{m}}{ }^{2}\right)}
\end{aligned}
$$

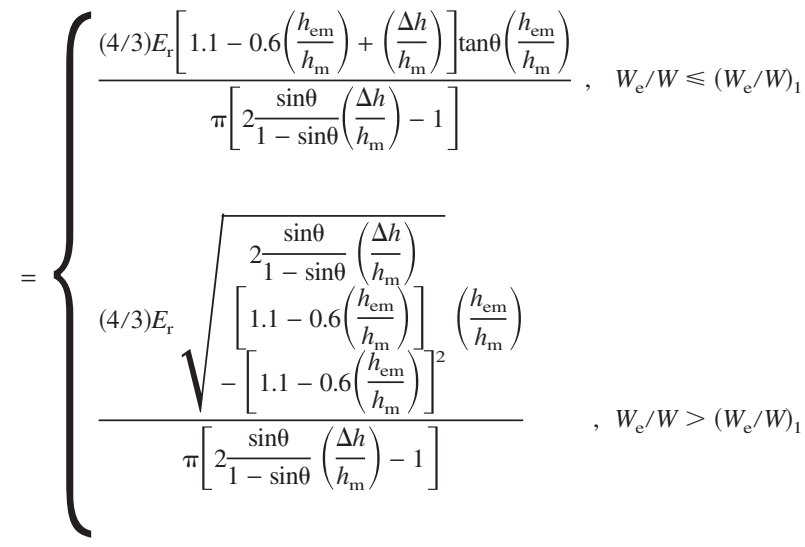

Substituting Eq. (27) into Eq. (33), a final relationship between Young's modulus and indentation parameters corresponding to the condition of $\Delta h / h_{m} \geqslant 1 / \sin \theta$ is obtained as 


$$
=\left\{\begin{array}{l}
\frac{\left[1.1-(2 / 3)\left(\frac{W_{\mathrm{e}}}{W}\right)+\left(\frac{\Delta h}{h_{\mathrm{m}}}\right)\right] \tan \theta\left(\frac{W_{\mathrm{e}}}{W}\right)}{0.675 \pi\left[2 \frac{\sin \theta}{1-\sin \theta}\left(\frac{\Delta h}{h_{\mathrm{m}}}\right)-1\right]}, W_{\mathrm{e}} / W \leqslant\left(W_{\mathrm{e}} / W\right)_{1} \\
\frac{\left(\frac{W_{\mathrm{e}}}{W}\right) \sqrt{2 \frac{\sin \theta}{1-\sin \theta}\left(\frac{\Delta h}{h_{\mathrm{m}}}\right)}}{\left[1.1-(2 / 3)\left(\frac{W_{\mathrm{e}}}{W}\right)\right]_{1}} \\
\frac{-\left[1.1-(2 / 3)\left(\frac{W_{\mathrm{e}}}{W}\right)\right]^{2}}{0.675 \pi\left[2 \frac{\sin \theta}{1-\sin \theta}\left(\frac{\Delta h}{h_{\mathrm{m}}}\right)-1\right]}, W_{\mathrm{e}} / W>\left(W_{\mathrm{e}} / W\right)_{1}
\end{array}\right.
$$

\section{C. $0.2<\Delta h / h_{\mathrm{m}}<1 / \sin \theta$}

Under this condition, we take the linear combination of indentation work derived in Section III.A and III.B as the indentation work of the presently investigated loading process, that is

$$
\begin{aligned}
W= & \left(\frac{1 / \sin \theta-\Delta h / h_{\mathrm{m}}}{1 / \sin \theta-0.2}\right) P_{\mathrm{m}} h_{\mathrm{m}} f_{\Delta 1}\left(\Delta h / h_{\mathrm{m}}\right) \\
& +\left[1-\left(\frac{1 / \sin \theta-\Delta h / h_{\mathrm{m}}}{1 / \sin \theta-0.2}\right)\right] \frac{1}{2.25} P_{\mathrm{m}} h_{\mathrm{m}} \\
& =P_{\mathrm{m}} h_{\mathrm{m}}\left[\left(\frac{1 / \sin \theta-\Delta h / h_{\mathrm{m}}}{1 / \sin \theta-0.2}\right) f_{\Delta 1}\left(\Delta h / h_{\mathrm{m}}\right)\right. \\
& \left.+\frac{1}{2.25}\left(\frac{\Delta h / h_{\mathrm{m}}-0.2}{1 / \sin \theta-0.2}\right)\right] .
\end{aligned}
$$

Let

$$
\begin{aligned}
f_{\Delta 2}\left(\Delta h / h_{\mathrm{m}}\right)= & \left(\frac{1 / \sin \theta-\Delta h / h_{\mathrm{m}}}{1 / \sin \theta-0.2}\right) f_{\Delta 1}\left(\Delta h / h_{\mathrm{m}}\right) \\
& +\frac{1}{2.25}\left(\frac{\Delta h / h_{\mathrm{m}}-0.2}{1 / \sin \theta-0.2}\right) .
\end{aligned}
$$

Then Eq. (35) can be rewritten as

$$
W=P_{\mathrm{m}} h_{\mathrm{m}} f_{\Delta 2}\left(\Delta h / h_{\mathrm{m}}\right) \text {. }
$$

For the unloading process, applying the similar analysis on Section III.B, the following results can be easily derived

$$
\begin{gathered}
\frac{h_{\mathrm{em}}}{h_{\mathrm{m}}}=2.5 f_{\Delta 2}\left(\Delta h / h_{\mathrm{m}}\right)\left(\frac{W_{\mathrm{e}}}{W}\right), \\
\left(W_{\mathrm{e}} / W\right)_{2}=\left(W_{\mathrm{e}} / W\right)_{\mid h_{\mathrm{cm}} / h_{0}=1}=\frac{1.1-\left(\Delta h / h_{\mathrm{m}}\right) \sin \theta}{1.5 f_{\Delta 2}\left(\Delta h / h_{\mathrm{m}}\right)},
\end{gathered}
$$

and

$$
\begin{aligned}
& H_{\mathrm{n}}=\frac{P_{\mathrm{m}}}{A\left(h_{\mathrm{m}}\right)}=\frac{(4 / 3) E_{\mathrm{r}} a_{\mathrm{m}} h_{\mathrm{em}}}{24.5\left(\Delta h+h_{\mathrm{m}}\right)^{2}} \\
& = \begin{cases}\frac{(4 / 3) E_{\mathrm{r}}\left[1.1-0.6\left(\frac{h_{\mathrm{em}}}{h_{\mathrm{m}}}\right)+\left(\frac{\Delta h}{h_{\mathrm{m}}}\right)\right] \tan \theta\left(\frac{h_{\mathrm{em}}}{h_{\mathrm{m}}}\right)}{24.5\left(1+\frac{\Delta h}{h_{\mathrm{m}}}\right)^{2}} & , W_{\mathrm{e}} / W \leqslant\left(W_{\mathrm{e}} / W\right)_{2} \\
\frac{(4 / 3) E_{\mathrm{r}} \sqrt{2 \frac{\sin \theta}{1-\sin \theta}\left(\frac{\Delta h}{h_{\mathrm{m}}}\right)}\left[\begin{array}{l}
\left.1.1-0.6\left(\frac{h_{\mathrm{em}}}{h_{\mathrm{m}}}\right)\right] \\
-\left[1.1-0.6\left(\frac{h_{\mathrm{em}}}{h_{\mathrm{m}}}\right)\right]^{2}
\end{array}\right.}{24.5\left(1+\frac{\Delta h}{h_{\mathrm{m}}}\right)^{2}} & , W_{\mathrm{e}} / W>\left(W_{\mathrm{e}} / W\right)_{2}\end{cases}
\end{aligned}
$$

Substituting Eq. (38) into Eq. (40), a final relationship between Young's modulus and indentation parameters corresponding to the condition of $0.2<\Delta h / h_{\mathrm{m}}<1 / \sin \theta$ is achieved; that is

$$
\begin{aligned}
& \frac{H_{\mathrm{n}}}{E_{\mathrm{r}}}
\end{aligned}
$$

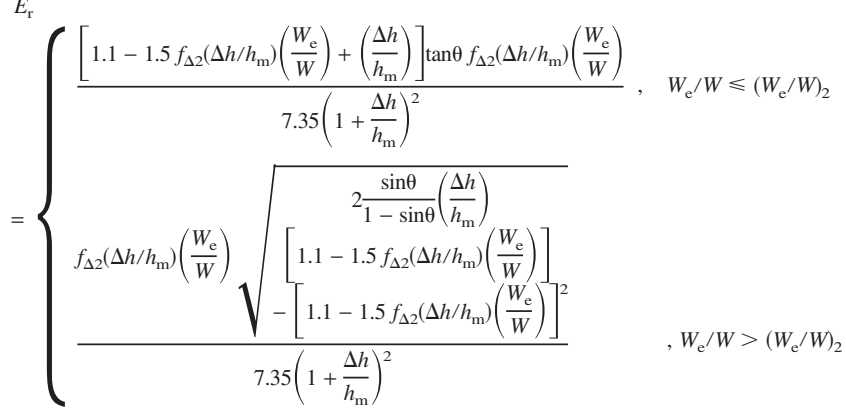

From Eqs. (22), (34), and (41), it is evident that for a definite ratio of $\Delta h / h_{\mathrm{m}}$ the ratio of $H_{\mathrm{n}} / E_{\mathrm{r}}$ is dependent only on the ratio of $W_{\mathrm{e}} / W$.

\section{NUMERICAL ANALYSIS}

We apply numerical analysis method to investigate the response of the material indented by the nonideally conical indenter within the framework of continuum mechanics. The indented material is assumed to behave as an isotropic and rate-independent solid, and obeys Von Mises yield criterion and pure isotropic hardening rule. The uniaxial stress-strain relations take the form of linear elasticity combined with the Hollomon's power law hardening, which can be expressed as

$$
\sigma=\left\{\begin{array}{l}
E \epsilon \quad, \epsilon \leqslant \epsilon_{\mathrm{y}} \\
\sigma_{\mathrm{y}}\left(\epsilon / \epsilon_{\mathrm{y}}\right)^{n}, \epsilon>\epsilon_{\mathrm{y}}
\end{array},\right.
$$

where $\sigma$ and $\epsilon$ are the true stress and true strain, $\sigma_{\mathrm{y}}$ and $\epsilon_{\mathrm{y}}=\sigma_{\mathrm{y}} / E$ are the yield stress and yield strain. When the indenter is considered as an elastic body, and the contact interface between the indenter and the indented material is assumed to be free of friction, the nominal hardness $H_{\mathrm{n}}$ 
and the work ratio $W_{\mathrm{e}} / W$, which are taken as the indentation responses, should be functions of the elastoplastic properties $\left(E, \nu, \sigma_{y}, n\right)$ of the tested material, the elastic properties $\left(E_{i}, v_{i}\right)$ and the absolute bluntness $(\Delta h)$ of the indenter, and the maximum indentation depth $\left(h_{m}\right)$. They can be described as

$$
\begin{gathered}
H_{\mathrm{n}}=f_{\mathrm{H}}\left(E, \nu, \sigma_{\mathrm{y}}, n, E_{\mathrm{i}}, \nu_{\mathrm{i}}, \Delta h, h_{\mathrm{m}}\right), \\
W_{\mathrm{e}} / W=f_{\mathrm{W}}\left(E, \nu, \sigma_{\mathrm{y}}, n, E_{\mathrm{i}}, v_{\mathrm{i}}, \Delta h, h_{\mathrm{m}}\right) .
\end{gathered}
$$

As with the Dao et al. analysis of sharp indentation, ${ }^{10}$ these two functions may be simplified by introducing $E_{\mathrm{r}}$ to combine the overall elasticity effects of the indenter and the indented material as

$$
\begin{gathered}
H_{\mathrm{n}}=f_{\mathrm{H}}\left(\sigma_{\mathrm{y}}, n, E_{\mathrm{r}}, \Delta h, h_{\mathrm{m}}\right), \\
W_{\mathrm{e}} / W=f_{\mathrm{W}}\left(\sigma_{\mathrm{y}}, n, E_{\mathrm{r}}, \Delta h, h_{\mathrm{m}}\right) .
\end{gathered}
$$

Applying $\Pi$ theorem of dimensional analysis, functions (45) and (46) can be rewritten in the following dimensionless forms:

$$
\begin{aligned}
H_{\mathrm{n}} E_{\mathrm{r}} & =\Phi_{\mathrm{H}}\left(\sigma_{\mathrm{y}} / E_{\mathrm{r}}, n, \Delta h / h_{\mathrm{m}}\right), \\
W_{\mathrm{e}} / W & =\Phi_{\mathrm{W}}\left(\sigma_{\mathrm{y}} / E_{\mathrm{r}}, n, \Delta h / h_{\mathrm{m}}\right) .
\end{aligned}
$$

It is obvious that to investigate the relationship between $H_{\mathrm{n}} / E_{\mathrm{r}}$ and $W_{\mathrm{e}} / W$ for a definite $\Delta h / h_{\mathrm{m}}$, the explicit solutions to the two functions (47) and (48) are required to be determined first, and to achieve this, commercial finite element code ABAQUS ${ }^{18}$ with the capability of large deformation analysis was used to simulate the nonideally conical indentation process. Considering $\sigma_{\mathrm{y}} / E_{\mathrm{r}}$ is an independent variable in Eqs. (47) and (48), so to vary $\sigma_{\mathrm{y}} / E_{\mathrm{r}}$, we may keep $E_{\mathrm{r}}$ unchanged by assigning fixed values to all the elastic properties $\left(E, \nu, E_{\mathrm{i}}, \nu_{\mathrm{i}}\right)$, and let $\sigma_{\mathrm{y}}$ to vary alone. In particular, $E_{\mathrm{i}}$ and $\nu_{\mathrm{i}}$ can be removed to

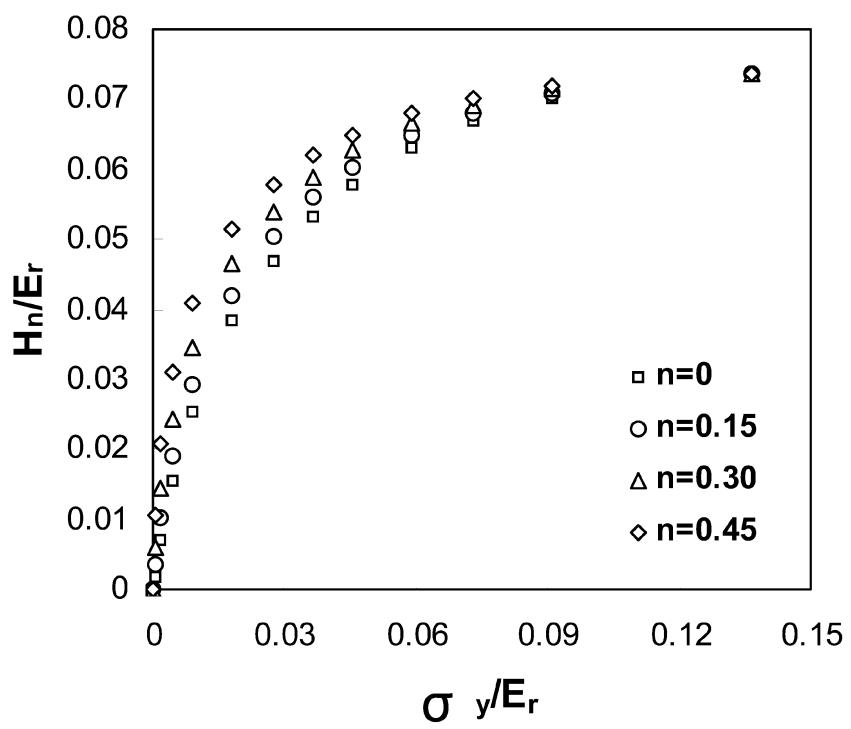

FIG. 3. Dependence of $H_{\mathrm{n}} / E_{\mathrm{r}}$ on $\sigma_{\mathrm{y}} / E_{\mathrm{r}}$ for different $n$ when $\left(\Delta h / h_{\mathrm{m}}\right)_{3}$ $=0.5$. get further simplicity by assuming that the indenter is rigid. The same way is applicable to vary $\Delta h / h_{\mathrm{m}}$ by fixing $h_{m}$ and changing $\Delta h$. As such, $E$, $v$, and $h_{\mathrm{m}}$ are fixed at $70 \mathrm{GPa}, 0.3$, and $1 \mu \mathrm{m}$, while $\sigma_{\mathrm{y}}, n$, and $\Delta h$ are scanned over the ranges of 35-10,500 $\mathrm{MPa}, 0-0.45$, and $0-12.4336 \mu \mathrm{m}$, respectively. In addition, in the finite element simulations, four-node axisymmetric elements are used, and the sizes of the elements in contact with the indenter are designed to be same and small to ensure that at least 30 nodes are in contact with the indenter. Obviously, to match with the simulation processes involving the use of non-ideally sharp indenters having different bluntnesses $\Delta h$ varying from 0 to $12.4336 \mu \mathrm{m}$, the width and height of the elements are needed to be adjusted accordingly from 0.06 and $0.15 \mu \mathrm{m}$, to 0.4 and $1 \mu \mathrm{m}$ respectively.

The indentation responses corresponding to seven relative bluntness values of $\Delta h / h_{\mathrm{m}}$ have been investigated by using finite element simulations. These relative bluntness values were selected as $0,0.2,0.5,1.0,1.5,3.0$, and 12.4336, and are represented by $\left(\Delta h / h_{\mathrm{m}}\right)_{j}$ with $j=$ $1,2, \ldots, 7$. As an example, the results of $H_{\mathrm{n}} / E_{\mathrm{r}}$ and $W_{\mathrm{e}} / W$ for different combinations of $\sigma_{\mathrm{y}} / E_{r}$ and $n$ obtained under the condition of $\left(\Delta h / h_{\mathrm{m}}\right)_{3}=0.5$ are plotted in Figs. 3 and 4 , respectively. Further, the relationship between $H_{\mathrm{n}} / E_{\mathrm{r}}$ and $W_{\mathrm{e}} / W$ was examined by plotting all data points in Fig. 5(c). The result confirms the existence of an approximate one-to-one correspondence between $H_{\mathrm{n}} / E_{\mathrm{r}}$ and $W_{\mathrm{e}} /$ $W$. As for the other relative bluntness values of $\Delta h / h_{\mathrm{m}}$ specified above, the same phenomena appeared, which is shown in Figs. 5(a), 5(b), and 5(d)-5(g). Consequently, seven approximate relationships between $H_{\mathrm{n}} / E_{\mathrm{r}}$ and $W_{\mathrm{e}} / W$ are established, and each of them can be fitted by a polynomial as

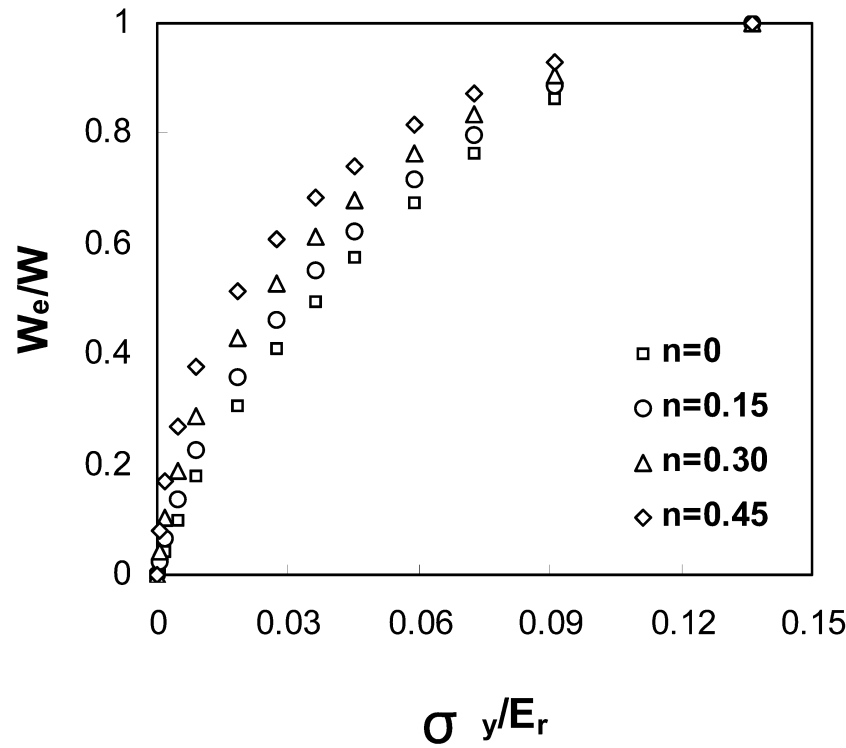

FIG. 4. Dependence of $W_{\mathrm{e}} / W$ on $\sigma_{\mathrm{y}} / E_{\mathrm{r}}$ for different $n$ when $\left(\Delta h / h_{\mathrm{m}}\right)_{3}$ $=0.5$. 

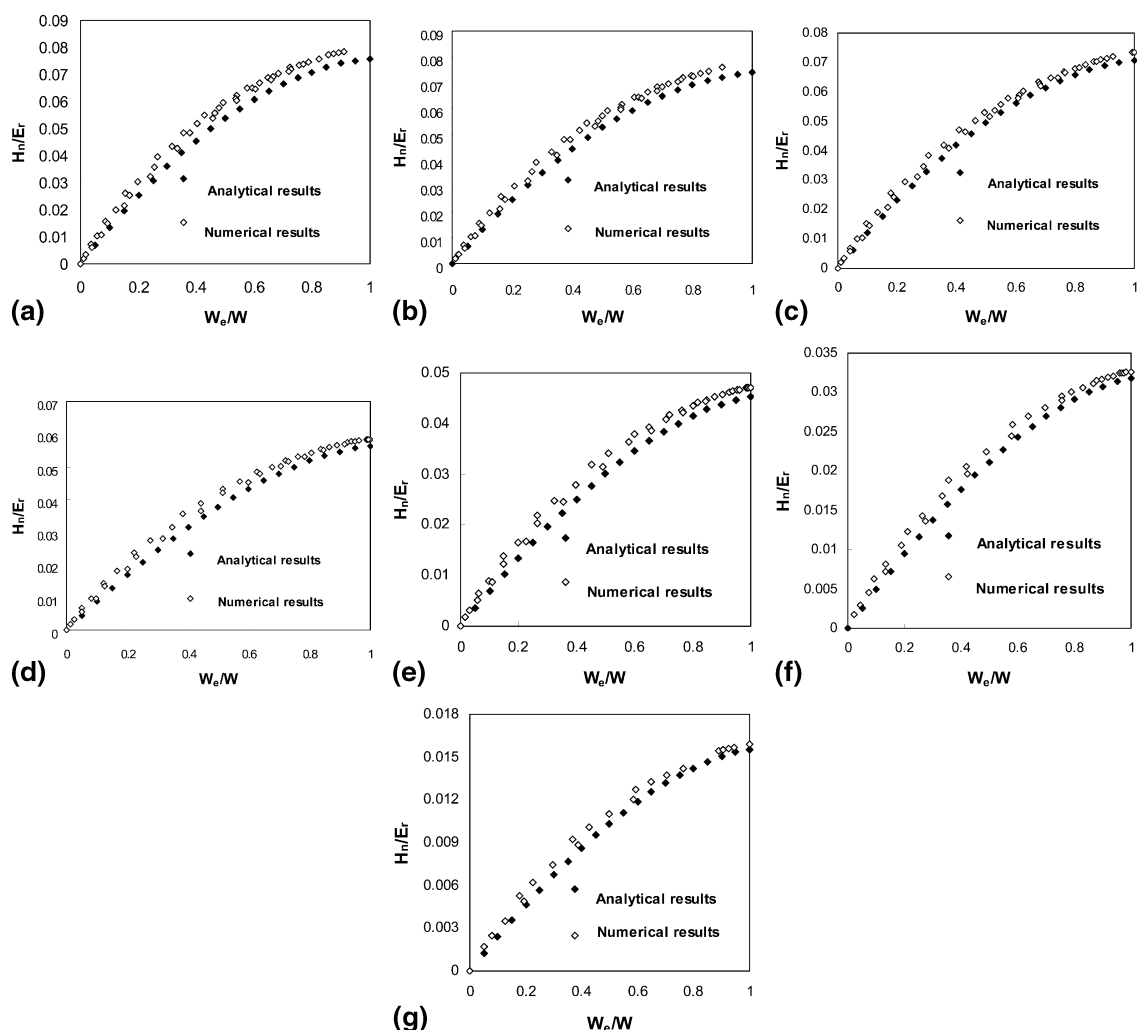

FIG. 5. Evidence illustrating the existence of an approximate one-to-one correspondence between $H_{\mathrm{n}} / E_{\mathrm{r}}$ and $W_{\mathrm{e}} / W$ under the condition of (a) $\left(\Delta h / h_{\mathrm{m}}\right)_{1}=0$, (b) $\left(\Delta h / h_{\mathrm{m}}\right)_{2}=0.2$, (c) $\left(\Delta h / h_{\mathrm{m}}\right)_{3}=0.5$, (d) $\left(\Delta h / h_{\mathrm{m}}\right)_{4}=1.0$, (e) $\left(\Delta h / h_{\mathrm{m}}\right)_{5}=1.5$, (f) $\left(\Delta h / h_{\mathrm{m}}\right)_{6}=3.0$, and (g) $\left(\Delta h / h_{\mathrm{m}}\right)_{7}=12.4336$.

TABLE I. The values of the coefficients $a_{i j}(i=1,2, \ldots, 6 ; j=1,2, \ldots, 7)$.

\begin{tabular}{ccccccr}
\hline \hline$j$ & $\left(\Delta h / h_{m}\right)_{j}$ & $a_{1 j}$ & $a_{2 j}$ & $a_{3 j}$ & $a_{4 j}$ & $a_{5 j}$ \\
\hline 1 & 0 & 0.18408 & -0.24835 & 0.50721 & -0.86118 & 0.75187 \\
2 & 0.2 & 0.17918 & -0.29111 & 0.76403 & -1.44113 & 1.34464 \\
3 & 0.5 & 0.16352 & -0.26383 & 0.65713 & -1.13560 & 0.96922 \\
4 & 1.0 & 0.12903 & -0.21498 & 0.54428 & -0.91821 & -0.25388 \\
5 & 1.5 & 0.10377 & -0.16829 & 0.39042 & -0.60740 & 0.76181 \\
6 & 3.0 & 0.07009 & -0.10262 & 0.22412 & -0.34838 & -0.31700 \\
7 & 12.4336 & 0.03560 & -0.06993 & 0.19772 & -0.34292 & 0.27533 \\
\hline \hline
\end{tabular}

$$
\begin{aligned}
\left(H_{\mathrm{n}} E_{\mathrm{r}}\right)_{j} & =\Psi_{j}\left(W_{\mathrm{e}} / W\right) \\
& =\sum_{i=1,2, \ldots, 6} a_{i j}\left(W_{\mathrm{e}} / W\right)^{i} \quad(j=1,2, \ldots, 7),
\end{aligned}
$$

where $\Psi_{j}(j=1,2, \ldots, 7)$ represents the functional relationship corresponding to a specific $\left(\Delta h / h_{\mathrm{m}}\right)_{j}$, and $a_{i j}$ 's $(i=1,2, \ldots, 6 ; j=1,2, \ldots, 7)$ are the fitting coefficients, which values are given in Table I. From above analysis, it is easy to deduce that for any definite $\Delta h / h_{\mathrm{m}}$ within the range of $0-12.4336, H_{\mathrm{n}} / E_{\mathrm{r}}$ should be a function of $W_{\mathrm{e}} / W$, i.e.,

$$
H_{\mathrm{n}} / E_{\mathrm{r}}=\Psi\left(W_{\mathrm{e}} / W\right)
$$

and the value of the function $\Psi\left(W_{\mathrm{e}} / W\right)$ can be determined from a series values of functions $\Psi_{j}\left(W_{\mathrm{e}} / W\right)(j=1,2, \ldots, 7)$ by interpolation.
Finally, for comparison, the analytical results calculated from the Eqs. (22), (34), and (41) for corresponding ratios of $\left(\Delta h / h_{\mathrm{m}}\right)_{j}(j=1,2, \ldots, 7)$ are also plotted in the Figs. 5(a) $-5(\mathrm{~g})$. Two kinds of results show that the relationship between $H_{\mathrm{n}} / E_{\mathrm{r}}$ and $W_{\mathrm{e}} / W$ revealed independently from the numerical calculations and the analytical analysis can be examined and supported by each other.

\section{CONCLUSIONS}

A new approximate relationship between Young's modulus and nonideally sharp indentation parameters has been revealed by both numerical calculations and analytical analysis. The relationship relates the ratio of nominal hardness/reduced Young's modulus $\left(H_{\mathrm{n}} / E_{\mathrm{r}}\right)$ with the ratio of elastic work/total work $\left(W_{\mathrm{e}} / W\right)$ for any 
definite ratio of the absolute bluntness to the maximum indentation depth $\left(\Delta h / h_{\mathrm{m}}\right)$. Based on this relationship, the determination of Young's modulus requires only the measurements of the nominal hardness and the indentation work. Unlike the initial unloading slope and the projected contact area, the nominal hardness and the indentation work can be measured with high precision. Thus, the relationship established in the study forms the basis of a method for determining Young's modulus of materials by nonideally sharp indentation, which is a promising substitution for the present analysis models. Results of detailed experimental investigations and comparison with different methods will be reported in a separate paper.

According to the results of finite element analysis of conical indentation using an indenter with an included half angle of $70.3^{\circ}$ performed by Bucaille et al., ${ }^{19}$ and spherical indentation performed by Mesarovic and Fleck, ${ }^{20}$ it is shown that the influence of any friction between an indenter and indented material on the loaddisplacement relationship, and hence the indentation work $W_{\mathrm{e}}$ or $W$ are just negligibly small, so that the validity of the newly revealed relationship between $H_{\mathrm{n}} / E_{\mathrm{r}}$ and $W_{\mathrm{e}} / W$ would not be affected by presence of any interfacial friction within normal range.

\section{ACKNOWLEDGMENTS}

The work described in this paper was substantially supported by a grant from the Research Grants Council of the Hong Kong Special Administrative Region (Project No. PolyU 5186/99P, account Code: B-Q281). This work was also supported by the Center for Smart Materials (Account Code: 1.A.310), an internal grant (Account Code: A-PE07), and another internal grant of The Hong Kong Polytechnic University.

\section{REFERENCES}

1. J.B. Pethica, R. Hutchings, and W.C. Oliver: Hardness measurement at penetration depth as small as 20nm. Philos. Mag. A 48, 593 (1983).

2. J.L. Loubet, J.M. Georges, O. Marchesini, and G. Meille: Vickers indentation curves of magnesium oxide $(\mathrm{MgO})$. J. Tribology 106, 43 (1984).

3. D. Newey, M.A. Wilkens, and H.M. Pollock: An ultra-low-load penetration hardness tester. J. Phys. E. Sci. Instrum. 15, 119 (1982).
4. W.C. Oliver and G.M. Pharr: An improved technique for determining hardness and elastic modulus using load and displacement sensing indentation experiments. J. Mater. Res. 7, 1564 (1992).

5. G.M. Pharr, W.C. Oliver, and F.R. Brotzen: On the generality of the relationship among contact stiffness, contact area, and elastic modulus during indentation. J. Mater. Res. 7, 613 (1992).

6. Y-T. Cheng, Z. Li, and C-M. Cheng: Scaling approach to modeling indentation measurements, in Fundamentals of Nanoindentation and Nanotribology II, edited by S.P. Baker, R.F. Cook, S.G. Corcoran, and N.R. Moody (Mater. Res. Soc. Symp. Proc. 649, Warrendale, PA, 2001), p. Q1.1.

7. Y-T. Cheng and C-M. Cheng: Relationships between hardness, elastic modulus, and the work of indentation. Appl. Phys. Lett. 73, 614 (1998).

8. A.E. Giannakopoulos and S. Suresh: Determination of elastoplastic properties by instrumented sharp indentation. Scripta Mater. 40, 1191 (1999).

9. T.A. Venkatesh, K.J. Van Vliet, A.E. Giannakopoulos, and S. Suresh: Determination of elasto-plastic properties by instrumented sharp indentation: guidelines for property extraction. Scripta Mater. 42, 833 (2000).

10. M. Dao, N. Chollacoop, K.J. Van Vliet, T.A. Venkatesh, and S. Suresh: Computational modeling of the forward and reverse problems in instrumented sharp indentation. Acta Mater. 49, 3899 (2001).

11. W.Y. Ni, Y.T. Cheng, C.M. Cheng, and D.S. Grummon: An energy-based method for analyzing instrumented spherical indentation experiments. J. Mater. Res. 19, 149 (2004).

12. Y-T. Cheng and C-M. Cheng: Further analysis of indentation loading curves: effect of tip rounding on mechanical property measurements. J. Mater. Res. 13, 1059 (1998).

13. W. Yu and J.P. Blanchard: An elastic-plastic indentation model and its solutions. J. Mater. Res. 11, 2358 (1996).

14. S. Timoshenko and J.N. Goodier: Theory of Elasticity (McGraw Hill, New York, 1951).

15. J.L. Loubet, M. Bauer, A. Tonck, S. Bec, and B. Gauthier-Manuel: Nanoindentation with a surface force apparatus, in Mechanical Properties and Deformation Behaviour of Materials Having Ultra-Fine Microstructures, edited by M.A. Nastasi, D.M. Parkin, and H. Gleiter (Kluwer Academic Publishers, Dordrecht, The Netherlands, 1993).

16. D. Tabor, The Hardness of Metals (Claredon Press, Oxford, U.K., 1951).

17. J. Alcala, A.E. Giannakopoulos, and S. Suresh: Continuous measurements of load-penetration curves with spherical microindenters and the estimation of mechanical properties. J. Mater. Res. 13, 1390 (1998).

18. ABAQUS: Version 6.2 (Hibbitt, Karlsson \& Sorensen, Inc., Pawtucket, RI, 2001).

19. J.L. Bucaille, S. Stauss, E. Felder, and J. Michler: Determination of plastic properties of metals by instrumented indentation using different sharp indenters. Acta Mater. 51, 1663 (2003).

20. S.Dj. Mesarovic and N.A. Fleck: Spherical indentation of elasticplastic solids. Proc. R. Soc. London. 455, 2707 (1999). 